Revista Brasileira de Cartografia

ISSN 1808-0936 | https://doi.org/10.14393/revbrascartogr

Sociedade Brasileira de Cartografia, Geodésia, Fotogrametria e Sensoriamento Remoto

\title{
Estimativa e Propagação de Valores de DCB C1C-C2W de um Receptor GPS com Vistas a Correção de Ordem Superior do Efeito Ionosférico
}

\author{
Estimation and Propagation of C1C-C2W DCB Values of a GPS Receiver for Higher \\ Order Correction of the Ionospheric Effects
}

Fabiane Piovesan de Moraes Cordeiro ${ }^{1}$, Tiago Lima Rodrigues ${ }^{2}$ e Luiz Danilo Damasceno Ferreira ${ }^{3}$.

1 Universidade Federal do Paraná, Programa de Pós-graduação em Ciências Geodésicas, Curitiba, Brasil. fapimo45@gmail.com. ORCID: https://orcid.org/0000-0002-0267-133X

2 Universidade Federal do Paraná, Programa de Pós-graduação em Ciências Geodésicas, Curitiba, Brasil. tiagorodrigues@ufpr.br. ORCID: https://orcid.org/0000-0002-3037-9037

3 Universidade Federal do Paraná, Programa de Pós-graduação em Ciências Geodésicas, Curitiba, Brasil.

luizdaniloferreira@gmail.com.

ORCID: https://orcid.org/0000-0002-8247-313X

Recebido: 02.2020 | Aceito: 06.2020

Resumo: Quando se almeja maior acurácia no posicionamento GNSS, é imprescindível a correção dos efeitos de ordem superior da refração ionosférica. O erro associado à ionosfera é diretamente proporcional ao conteúdo total de elétrons (Total Electron Content - TEC) presentes na atmosfera e inversamente proporcional à frequência do sinal. Ao usar a combinação linear livre de geometria com as observações advindas dos códigos, o cálculo do TEC é influenciado pelo erro sistemático conhecido como tendência diferencial devido ao atraso do código (Differential Code Bias - DCB). Esta pesquisa tem como principal objetivo a determinação do DCB C1C-C2W de um receptor GPS, utilizando a técnica da Simples Diferença, para utilização no cálculo do TEC e na correção dos efeitos de ordem superior da refração ionosférica diretamente em campo. Os experimentos foram realizados no contexto do PPP (Posicionamento por Ponto Preciso). Experimentos adicionais considerando a propagação dos valores de DCB por três e quatro semanas foram conduzidos. Isso, a fim de verificar a possibilidade de diminuir a frequência de idas a campo para o cálculo dos valores de DCB. Os resultados obtidos considerando-se a correção de ordem superior da refração ionosférica mostram uma melhora na ordem do milímetro na direção leste-oeste e na direção normal ao elipsoide, quando comparados com o processamento considerando apenas as correções de primeira ordem. Para a componente norte-sul, a melhora apresentou-se na ordem do centímetro. Quando utilizados os DCBs propagados, os resultados apresentaram uma acurácia média no PPP de $0,2 \mathrm{~cm}$ para latitude, $1,4 \mathrm{~cm}$ para longitude e $1,5 \mathrm{~cm}$ para altitude.

Palavras-chave: DCB. TEC. GNSS. Efeitos de ordem superior na ionosfera. PPP.

\begin{abstract}
When higher accuracy is sought in the GNSS positioning, it is imperative to correct the higher order effects of ionospheric refraction. The error associated with the ionosphere is directly proportional to the total electron content (TEC) present in the atmosphere and inversely proportional to the signal frequency. When using the geometry free linear combination with the codes the calculation of TEC is influenced by the systematic error known as the differential code bias (DCB). This research has as main objective the determination of the C1C-C2W DCB values, using Single Difference technique of a GPS receiver for use in the calculation of the TEC and in the correction of the higher order effects of the ionospheric refraction. Experiments have been performed in the PPP (Precise Point Positioning) context. Additional experiments considering the propagation of DCB values for up to four weeks were conducted. This, in order to verify the possibility of decreasing the frequency of calculation of DCB values in situ. The results obtained considering the correction of the higher order of the ionospheric refraction show a better order of the millimeter in the east-west direction and in the normal direction to the ellipsoid, when compared with the processing considering only the first order corrections. For the north-south component, the improvement was in the order of centimeter. When using the propagated DCBs, the results showed an average accuracy in the PPP of $0.2 \mathrm{~cm}$ for latitude, $1.4 \mathrm{~cm}$ for longitude and $1.5 \mathrm{~cm}$ for altitude.
\end{abstract}

Keywords: DCB. TEC. GNSS. Higher-order ionospheric effects. PPP. 


\section{INTRODUÇÃO}

Mesmo com a desativação da SA (Selective Availability), os sinais provenientes dos satélites do sistema GPS (Global Positioning System) ainda passam por interferências, as quais ocasionam erros no posicionamento. Atualmente, uma das fontes de erro no posicionamento com GPS é a camada da ionosfera, que é caracterizada como um meio dispersivo composta por íons e elétrons livres que afetam a propagação de ondas eletromagnéticas, as quais são transmitidas pelos satélites (CAMARGO, 1999).

O erro devido à refração ionosférica é diretamente proporcional ao TEC presente ao longo da trajetória percorrida pelo sinal na ionosfera, que varia no tempo e no espaço e inversamente proporcional ao quadrado da frequência do sinal (LEICK, 1995). O TEC é influenciado por variáveis como: ciclo solar, época do ano, hora do dia, localização geográfica, atividade geomagnética, dentre outros (KLOBUCHAR, 1991).

Utilizando-se de receptores de dupla frequência é possível efetuar correções do efeito da ionosfera, pois o erro depende da frequência do sinal. Ao realizar a combinação linear livre de ionosfera entre as portadoras L1 e L2, é possível eliminar os efeitos de primeira ordem da refração ionosférica, os quais representam $99 \%$ do atraso provocado nas medidas e o restante é atribuído aos efeitos de ordem superior (MARQUES et al., 2014).

Os efeitos de segunda e terceira ordem geralmente são negligenciados no processamento dos dados GNSS (Global Navigation Satellite Systems). Estes efeitos devem ser corrigidos quando há exigência de resultados com alta acurácia, pois a não correção desses efeitos implica em erros residuais nas coordenadas da ordem de milímetros, podendo chegar a centímetros (FRITSCHE et al., 2005). Em razão disto, o IERS (International Earth Rotation and Reference Systems Service) recomenda por meio das convenções de 2010 que os centros de processamento de dados do ITRF (International Terrestrial Reference Frame) empreguem as correções dos efeitos ionosféricos de segunda e terceira ordem (IERS, 2010).

O atraso no sinal GNSS que ocorre em função da tendência diferencial do código (DCB) é considerado um efeito instrumental decorrente da diferença entre o tempo de propagação das diferentes portadoras no hardware tanto dos satélites quanto dos receptores (HEGARTY et al., 2005; HONG, 2007). Pode-se dizer que a estimativa dos valores de DCBs é uma parte significativa da modelagem da ionosfera utilizando GNSS. O IGS (International GNSS Service) divulga os valores de DCB para o caso dos satélites GNSS e para os receptores que fazem parte da rede IGS por meio dos arquivos IONEX (IONosphere map EXchange format).

O cálculo correto dos DCBs também é essencial para os serviços de navegação e posicionamento, principalmente para os usuários que requerem maior acurácia, pois melhora a estimativa do erro do relógio do receptor e auxilia na resolução das ambiguidades quando não se usa a observável ion-free. Além disso, os DCBs também são fatores importantes em aplicações precisas, como sondagem da ionosfera baseada em GNSS (HERNÁNDEZ-PAJARES et al., 1999; SCHAER, 1999), posicionamento por ponto preciso (PPP) e resolução de ambiguidade no PPP, bem como estimativa de relógio de satélite GNSS (COLLINS et al. 2010; GE et al. 2017; LI et al., 2017).

Sabe-se que os DCBs variam no tempo e por isso há a necessidade de estimá-los periodicamente. Este procedimento faz com que mais trabalho de campo seja necessário. A fim de contornar isto, torna-se viável a análise da aplicação de propagação numérica nos valores estimados de DCB para uma determinada época. Assim, analisou-se a possibilidade de se estimar o DCB ocasionalmente.

Esta pesquisa visa analisar a aplicação do método da simples diferença baseada na utilização de dois receptores, formando uma linha de base curta. A estação base utilizada é a estação UFPR (Universidade Federal do Paraná), parte integrante da rede IGS e também da RBMC (Rede Brasileira de Monitoramento Contínuo da rede GNSS), cujo valor do DCB do receptor para esta estação é calculado pelo IGS e utilizado pelos autores como referência. Logo, torna-se possível a estimativa do DCB do receptor itinerante. Diante disso, obteve-se uma série temporal de valores de DCB deste receptor e, com dados de algumas épocas, fez-se a propagação numérica dos valores, ao longo de um determinado intervalo de tempo. Os valores obtidos tanto no cálculo quanto na propagação foram utilizados para estimativa do TEC no cálculo dos efeitos de ordem superior da refração ionosférica, no contexto do PPP (Posicionamento por Ponto Preciso), consequentemente contribuindo para a melhoria e obtenção de maior acurácia no posicionamento. 


\section{REVISÃO DE LITERATURA}

\subsection{Efeitos de ordem superior}

Bassiri e Hajj (1993) e Odijk (2002) descrevem os efeitos de primeira, segunda e terceira ordem da refração ionosférica para a pseudodistância na frequência $\mathrm{f}_{\mathrm{Li}}(\mathrm{i}=1,2)$, como segue nas Eq. $(1,2$ e 3):

$$
\begin{gathered}
\mathrm{I}_{\mathrm{gLi}}^{(1)}=\frac{\mathrm{A}}{2 \mathrm{f}_{\mathrm{Li}}^{2}} \mathrm{TEC}=\frac{40,3}{\mathrm{f}_{\mathrm{Li}}^{2}} \mathrm{TEC}, \\
\mathrm{I}_{\mathrm{gLi}}^{(2)}=\frac{\mathrm{eA}}{\mathrm{f}_{\mathrm{Li}}^{3} 2 \pi \mathrm{m}_{\mathrm{e}}}\|\mathrm{B}\||\cos \theta| \mathrm{TEC}, \\
\mathrm{I}_{\mathrm{gLi}}^{(3)}=\frac{3 \mathrm{~A}^{2}}{8 \mathrm{f}_{\mathrm{Li}}^{4}} \eta N_{\mathrm{e}, \max } \mathrm{TEC},
\end{gathered}
$$

onde, $\mathrm{A}=\frac{\mathrm{e}^{2}}{4 \pi \mathrm{m}_{\mathrm{e}} \varepsilon_{0}}$, considerando $\mathrm{A} \approx 80,6 \mathrm{~m}^{3} / \mathrm{s}^{2}, \mathrm{~N}_{\mathrm{e}}$ é a densidade de elétrons livres em $\mathrm{m}^{3}, \mathrm{e}=1,60218 \times 10^{-}$ ${ }^{19}$ Coulomb para a carga do elétron, $\mathrm{m}_{\mathrm{e}}=9,10939 \times 10^{-31} \mathrm{~kg}$ para a massa do elétron, $\varepsilon_{0}=8,85419 \times 10^{-12}$ Farad/metro para a permissividade do espaço livre, B é o vetor de indução geomagnética e $\theta$ é o ângulo que fornece a direção de propagação do sinal em relação ao vetor indução geomagnética (B).

Sabe-se que o efeito ionosférico de primeira ordem da fase é igual ao do código, porém com sinais opostos. O mesmo ocorre para os efeitos de segunda e terceira ordem, contudo para a fase, esses efeitos representam, respectivamente, a metade e a terça parte dos efeitos do código (ODIJK, 2002).

Apesar do cálculo do efeito de terceira ordem ser análogo aos de primeira e segunda ordens, ele é uma função da densidade máxima de elétrons $N_{e, \text { max }}$ e um fator de forma $\eta$, cujo valor de 0,66 foi obtido por Odijk (2002).

No caso da correção dos efeitos de primeira ordem, para receptores de dupla frequência, uma alternativa é utilizar a combinação linear livre de ionosfera, que combina linearmente as frequências L1 e L2 das observáveis. Nas Eq. (4 e 5) são apresentadas as combinações lineares livre de ionosfera (ion-free) para a fase da onda portadora $\left(\varphi_{\mathrm{IF}}\right)$ e da pseudodistância $\left(\mathrm{PD}_{\mathrm{IF}}\right)$ :

$$
\begin{gathered}
\mathrm{PD}_{\mathrm{IF}}=\mathrm{m}_{1} \mathrm{PD}_{\mathrm{L} 1}+\mathrm{m}_{2 \mathrm{PD}} \mathrm{PD}_{\mathrm{L} 2}, \\
\varphi_{\mathrm{IF}}=\mathrm{m}_{1} \varphi_{\mathrm{L} 1}+\mathrm{m}_{2 \varphi} \varphi_{\mathrm{L} 2},
\end{gathered}
$$

onde, $\mathrm{m}_{1}$ e $\mathrm{m}_{2}$ são os coeficientes multiplicadores da combinação.

Para que os efeitos de primeira ordem da refração ionosférica sejam eliminados, faz-se necessário que:

1) ao se realizar a combinação, os termos $I_{\varphi \mathrm{L} 1, \mathrm{~L} 2}$ e $\mathrm{I}_{\mathrm{PDL} 1, \mathrm{~L} 2}$ devem ser cancelados. Para isso, tem-se a Eq. (6):

$$
\frac{\mathrm{m}_{1}}{\mathrm{f}_{\mathrm{L} 1}}+\frac{\mathrm{m}_{2}}{\mathrm{f}_{\mathrm{L} 2}}=0
$$

2) a frequência da combinação linear deve ser a mesma da portadora L1, mas sem o efeito da refração ionosférica. Para isso, tem-se a Eq. (7):

$$
\mathrm{m}_{1} \mathrm{f}_{\mathrm{L} 1}+\mathrm{m}_{2} \mathrm{f}_{\mathrm{L} 2}=\mathrm{f}_{1} \text {, }
$$

Ao considerar as duas condições, os coeficientes $\mathrm{m}_{1}$ e $\mathrm{m}_{2}$ para o caso da fase da onda portadora são calculados nas Eq. (8 e 9) por (GOAD; YANG, 1994):

$$
\mathrm{m}_{1 \varphi}=\frac{\mathrm{f}_{1}^{2}}{\left(\mathrm{f}_{1}^{2}-\mathrm{f}_{2}^{2}\right)} \cong 2,5457,
$$




$$
\mathrm{m}_{2 \varphi}=\frac{\mathrm{f}_{1} \mathrm{f}_{2}}{\left(\mathrm{f}_{1}^{2}-\mathrm{f}_{2}^{2}\right)} \cong-1,9837
$$

No caso da pseudodistância, o índice $\mathrm{m}_{1}$ é adotado igual ao da fase e então obtém-se o índice $\mathrm{m}_{2}$, pelas Eq. (10 e 11):

$$
\begin{gathered}
\mathrm{m}_{1 \mathrm{PD}}=\frac{\mathrm{f}_{1}^{2}}{\left(\mathrm{f}_{1}^{2}-\mathrm{f}_{2}^{2}\right)} \cong 2,5457, \\
\mathrm{~m}_{2 \mathrm{PD}}=\frac{\mathrm{f}_{1}^{2}}{\left(\mathrm{f}_{1}^{2}-\mathrm{f}_{2}^{2}\right)} \cong-1,5457,
\end{gathered}
$$

Sendo assim, as Eq. (4 e 5) tornam-se as Eq. (12 e 13):

$$
\begin{gathered}
\mathrm{PD}_{\mathrm{IF}}=2,5457 \mathrm{PD}_{\mathrm{L} 1}-1,5457 \mathrm{PD}_{\mathrm{L} 2} \\
\varphi_{\mathrm{IF}}=2,5457 \varphi_{\mathrm{L} 1}-1,9837 \varphi_{\mathrm{L} 2}
\end{gathered}
$$

Para o cálculo dos efeitos de ordem superior, Marques (2008) desenvolveu o software RINEX_HO, o qual gera um novo arquivo RINEX com as observáveis corrigidas dos efeitos.

\subsection{Cálculo do TEC com GNSS}

Um parâmetro importante que descreve o efeito da ionosfera nos sinais GNSS é o TEC, o qual representa o número de elétrons contidos em uma coluna com seção transversal de $1 \mathrm{~m}^{2}$ que se estende desde o receptor até o satélite e normalmente apresentado em unidades de TEC (TECU), onde 1 TECU corresponde a $1 \times 10^{16}$ elétrons $/ \mathrm{m}^{2}$. Ainda, Matsuoka e Camargo (2004) mostraram como converter o TEC em erro na distância medida com a fase e o código nas frequências L1 e L2, em metros, onde para L1, 1 TECU =0,16 m e para L2, 1 TECU $=0,27 \mathrm{~m}$.

Dispondo-se de receptores de dupla frequência, o TEC pode ser calculado pela combinação linear livre de geometria, formada pela subtração das observáveis provenientes das duas frequências. Esta combinação é assim chamada, uma vez que ao ser realizada, ocorre a eliminação da parte geométrica das equações, juntamente com a parte de erros de relógios, refração troposférica, e todos os demais erros não dependentes da frequência. Há também os erros referentes aos atrasos instrumentais interfrequência (Inter-Frequency Bias IFB) do satélite e do receptor, causados pela diferença entre os caminhos percorridos pelas portadoras L1 e L2, afetando o tempo de propagação do sinal. No caso dos códigos, o IFB é denominado de tendência diferencial do código (DCB). No caso das fases, o IFB é denominado tendência diferencial da fase (Differential Phase Bias - DPB). Por exemplo, nas Eq. (14 e 15), no caso das portadoras L1 e L2 tem-se para a pseudodistância e fase (MATSUOKA; CAMARGO, 2004):

$$
\begin{gathered}
\mathrm{TEC}_{\mathrm{r}}^{\mathrm{s}}=\frac{\mathrm{f}_{1}^{2} \mathrm{f}_{2}^{2}}{40,3\left(\mathrm{f}_{1}^{2}-\mathrm{f}_{2}^{2}\right)}\left[\left(\mathrm{PD}_{2 \mathrm{r}}^{\mathrm{s}}-\mathrm{PD}_{1 \mathrm{r}}^{\mathrm{s}}\right)-\mathrm{c}\left(\Delta \mathrm{b}_{\mathrm{PD}}^{\mathrm{s}}+\Delta \mathrm{b}_{\mathrm{r}, \mathrm{PD}}\right)-\mathrm{e}_{\mathrm{PD}_{12}}\right] \\
\mathrm{TEC}_{\mathrm{r}}^{\mathrm{s}}=-\frac{\mathrm{f}_{1}^{2} \mathrm{f}_{2}^{2}}{40,3\left(\mathrm{f}_{1}^{2}-\mathrm{f}_{2}^{2}\right)}\left[\left(\lambda_{2} \varphi_{2 \mathrm{r}}^{\mathrm{s}}-\lambda_{1} \varphi_{1 \mathrm{r}}^{\mathrm{s}}\right)-\left(\lambda_{1} \mathrm{~N}_{1 \mathrm{r}}^{\mathrm{s}}-\lambda_{2} \mathrm{~N}_{2 \mathrm{r}}^{\mathrm{s}}\right)-\mathrm{c}\left(\Delta \mathrm{b}_{\varphi}^{\mathrm{s}}+\Delta \mathrm{b}_{\mathrm{r}, \varphi}\right)-\mathrm{e}_{\varphi_{12}}\right]
\end{gathered}
$$

onde $f_{1}$ e $f_{2}$ são as frequências da onda das portadoras $L 1$ e $L 2$, respectivamente, $\mathrm{e}_{\mathrm{PD}_{12}}$ representa os erros sistemáticos não eliminados na combinação linear e erros aleatórios, $\lambda_{1}$ e $\lambda_{2}$ são os comprimentos da onda das portadoras L1 e L2, respectivamente, $\mathrm{N}_{1 \mathrm{r}}^{\mathrm{S}}$ e $\mathrm{N}_{2 \mathrm{r}}^{\mathrm{s}}$ simbolizam as ambiguidades da fase das portadoras L1 e L2, respectivamente, $\Delta \mathrm{b}_{\mathrm{PD}}^{\mathrm{s}}$ e $\Delta \mathrm{b}_{\mathrm{r}, \mathrm{PD}}$ são os DCB de satélite e receptor, respectivamente, e; $\Delta \mathrm{b}_{\varphi}^{\mathrm{s}}$ e $\Delta \mathrm{b}_{\mathrm{r}, \varphi}$ são os IFB para a fase de satélite e receptor, respectivamente e $\mathrm{e}_{\varphi_{12}}$ representa os erros sistemáticos não eliminados na combinação linear e erros aleatórios.

Cabe ressaltar que estas quantidades influenciam na estimativa do TEC. Segundo Wilson e Mannucci (1994), o TEC, quando calculado a partir de medições GNSS, pode resultar em erros de \pm 3 ns até $\pm 10 \mathrm{ns,}$ respectivamente, quando o valor do DCB do satélite ou do receptor é ignorado. Desta forma, geralmente, os 
DCB dos satélites e receptores são parâmetros estimados, juntamente com o TEC nos modelos ionosféricos (PROL; CAMARGO, 2014). De acordo com as observáveis utilizadas nos cálculos, têm-se diferentes DCB, como o DCB entre o código P1 e o código P2 (DCBP1P2), o DCB entre os códigos C/A e P2 (DCBC1P2), ou o DCB entre os códigos C/A e P1 (DCBC1P1).

\subsection{Cálculo dos DCBs dos receptores}

Choi et al. (2011) mostraram que os DCBs, tanto de satélites quanto de receptores, estimados a partir de medições GNSS, podem atingir até algumas dezenas de nanossegundos. Os DCBs de satélites GNSS têm uma estabilidade de longo prazo, com um desvio padrão de cerca de 0,2 ns (WILSON; MANNUCCI, 1994). Os valores de DCB dos receptores tendem a variar mais do que os dos satélites, como visto, por exemplo, em Prol e Camargo (2014).

Para a estimativa do DCB de receptores é baseada na aplicação da Simples Diferença (SD) entre dois receptores dispostos em linhas de base curtas (CAMARGO et al., 2012). Uma vez que a influência da ionosfera é considerada a mesma para as duas estações, não há a utilização de um modelo ionosférico, e, por consequência não é necessário o conhecimento do valor do TEC e nem do DCB do satélite. Ambos são cancelados na formação da SD, onde se considera que os sinais GNSS são rastreados simultaneamente em cada um dos receptores. Porém, ao se realizar a mesma, obtém-se a diferença entre o DCB do receptor da base e o DCB do receptor itinerante. Isto é, um valor relativo de DCB entre as estações. Somente se o valor do DCB do receptor da base for conhecido, ou arbitrado com um valor de referência, o valor do DCB do receptor itinerante será estimado. Cabe ressaltar que os valores de erros de multicaminhamento e de ruído dos receptores estarão presentes. Neste caso, tem-se para receptores r1 e r2, e um satélite s a Eq. (16):

$$
\begin{aligned}
& \mathrm{FSD}\left(\mathrm{PD}_{2 \mathrm{r} 1}^{\mathrm{s} 1} \mathrm{PD}_{1 \mathrm{r} 1}^{\mathrm{s}}\right),\left(\mathrm{PD}_{2 \mathrm{r} 2}^{\mathrm{s}} \mathrm{PD} \mathrm{Lr}_{2}^{\mathrm{s}}\right) \\
& =\left[\mathrm{TEC}_{\mathrm{r} 2}+\mathrm{F}\left(\mathrm{c} \Delta \mathrm{b}_{\mathrm{r} 2, \mathrm{PD}}+\mathrm{c} \Delta \mathrm{b}_{\mathrm{PD}}^{\mathrm{s}}+\mathrm{e}_{\mathrm{PDr} 2}\right)\right] \\
& -\left[\mathrm{TEC}_{\mathrm{r} 1}+\mathrm{F}\left(\mathrm{c} \Delta \mathrm{b}_{\mathrm{r} 1, \mathrm{PD}}+\mathrm{c} \Delta \mathrm{b}_{\mathrm{PD}}^{\mathrm{s}}+\mathrm{e}_{\mathrm{PDr} 1}\right)\right] \text {, }
\end{aligned}
$$

onde $\mathrm{SD}_{\left(\mathrm{PD}_{2 \mathrm{r} 1}^{\mathrm{S}} \mathrm{PD}_{1 \mathrm{r} 1}^{\mathrm{s}}\right),\left(\mathrm{PD}_{2 \mathrm{r} 2}^{\mathrm{s}} \mathrm{PD}_{1 \mathrm{r} 2}^{\mathrm{s}}\right)}$ é a $\mathrm{SD}$ das combinações livre de geometria para os receptores $\mathrm{r} 1$ e $\mathrm{r} 2$. Uma vez que TECr1 = TECr2, tem-se as Eq. (17 e 18):

sendo:

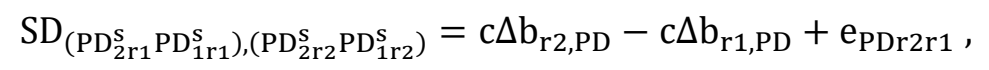

$$
\mathrm{e}_{\mathrm{PDr} 2 \mathrm{r} 1}=\mathrm{e}_{\mathrm{PDr} 2}-\mathrm{e}_{\mathrm{PDr} 1}
$$

Tendo-se o valor do DCB do receptor r1, estima-se o valor do DCB do receptor r2, em metros, para uma determinada época pela Eq. (19):

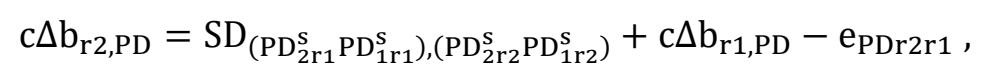

Dentro do contexto desta metodologia, ressalta-se que quanto maior a linha de base, maior a diferença no comportamento da ionosfera nas estações e mais erro será propagado para o valor do DCB do receptor. Como exemplo de aplicação desta metodologia, cita-se Hong et al. (2008), que estabeleceram linhas de base de até 200 km, utilizando estações da rede CORS (Continuously Operating Reference Stations) em Ohio.

\section{METODOLOGIA}

Primeiramente, foram realizados os cálculos dos valores de DCB de um receptor GPS com base no método da simples diferença. Posteriormente, realizou-se a etapa do cálculo dos valores de TEC e da correção dos efeitos de ordem superior da refração ionosférica nas observáveis dos arquivos RINEX, para cada dia de rastreio.

Após estas etapas, a fim de investigar a ideia de otimização do tempo em campo, realizou-se a 
propagação numérica dos valores de DCB. Para validar este experimento, testes foram realizados com base nos valores provenientes dos arquivos IONEX para a estação UFPR. Em seguida, a partir do software RINEX_HO foram corrigidos os efeitos de ordem superior da refração ionosférica. Por fim, foram feitos processamentos no contexto do PPP, utilizando o software RTKLIB 2.4.2, desenvolvido por Takasu (2009), com a finalidade de analisar as possíveis melhorias na acurácia planialtimétrica com as correções dos efeitos de ordem superior da refração ionosférica, usando-se os valores de TEC corrigidos usando-se os DCBs obtidos com o cálculo e com a propagação. Neste contexto, foram organizados os experimentos delineados no Quadro 1.

Quadro 1 - Experimentos e suas características.

\begin{tabular}{|c|c|}
\hline Experimento & Características \\
\hline 1 & PPP com correção dos efeitos de primeira ordem da refração ionosférica \\
\hline 2 & $\begin{array}{l}\text { PPP com correção de ordem superior da refração ionosférica com a determinação do TEC utilizando DCB } \\
\text { (receptor) calculado }\end{array}$ \\
\hline 3 & $\begin{array}{l}\text { PPP com correção de ordem superior da refração ionosférica com a determinação do TEC utilizando DCB } \\
\text { (receptor) propagado por três semanas }\end{array}$ \\
\hline 4 & $\begin{array}{l}\text { PPP com correção de ordem superior da refração ionosférica com a determinação do TEC utilizando DCB } \\
\text { (receptor) propagado por quatro semanas }\end{array}$ \\
\hline
\end{tabular}

Fonte: Os autores (2020).

O levantamento dos dados foi feito em um dos pilares de centragem forçada da Base de Calibração de Antenas GNSS (BCAL), o pilar 1000, nas dependências do Centro Politécnico da Universidade Federal do Paraná, Curitiba. Para a aquisição das observações, foi utilizado o receptor GPS Leica 1200 com o método relativo estático, cuja estação base é a RBMC UFPR, em 19 sessões de aproximadamente 24 horas cada, com intervalo de gravação dos dados de 15 segundos e máscara de elevação configurada para $10^{\circ}$. As sessões foram feitas a cada sete dias, totalizando um período de cinco meses de coleta. Nesta configuração, a linha de base possui aproximadamente 40 metros que, apesar de ser considerada curta, gera um resíduo no cálculo do DCB. Devido à questão de segurança para o equipamento, foi necessário que o mesmo fosse instalado no pilar mencionado anteriormente na lage do prédio, a linha de base não pode ser menor. Porém, recomenda-se que a linha de base seja a menor possível, para evitar tais resíduos. Os arquivos RINEX destes rastreios foram gerados com o software Leica Geo Office.

Com o objetivo de calcular o DCB, foi desenvolvida uma rotina em ambiente MATLAB, seguindo a formulação apresentada na Eq. (11), utilizando a pseudodistância filtrada pela fase. Com os valores de DCB estimados a cada época do rastreio, foram calculadas as médias diárias conforme Eq. (20):

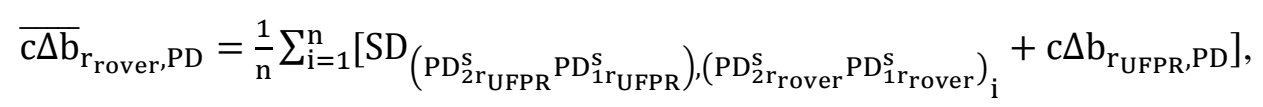

onde $\overline{\mathrm{c} \Delta \mathrm{b}}_{\mathrm{r}_{\text {rover, }} \mathrm{PD}}$ é a média diária dos $\mathrm{DCBs}$ do receptor itinerante em metros, $\mathrm{SD}\left(\mathrm{PD}_{2 \mathrm{r}_{\mathrm{UFPR}}}^{\mathrm{s}} \mathrm{PD}_{1 \mathrm{r}_{\mathrm{UPPR}}}^{\mathrm{s}}\right),\left(\mathrm{PD}_{2 \mathrm{r}_{\text {rover }}}^{\mathrm{s}} \mathrm{PD}_{\left.1 \text { rover }_{\text {rov }}\right)_{\mathrm{i}}}^{\mathrm{s}}\right.$ é a iésima simples diferença em metros, $\mathrm{n}$ é o número de épocas do rastreio, $\mathrm{c} \Delta \mathrm{b}_{\mathrm{r}_{\mathrm{UFP}}, \mathrm{PD}}$ é o DCB da estação UFPR em metros.

Por conta das variações nos valores do DCB dos receptores, o mesmo deve ser calculado previamente toda vez que houver a necessidade de cálculo do TEC para a correção dos efeitos de ordem superior da refração ionosférica. Para evitar demasiadas idas a campo, analisou-se a ideia de utilizar os valores de DCB propagados via integração numérica.

A integração numérica é caracterizada por ser um processo computacional para a estimativa de um valor numérico de uma função sobre um conjunto matemático. Com os valores semanais de DCB do receptor Leica 1200 calculados, fez-se a propagação por integração numérica de algumas semanas específicas para que fosse possível uma investigação. O método de integração numérica utilizado foi o Runge-Kutta de ordem 7(8), com coeficientes de Fehlberg (FEHLBERG, 1968), com passo de integração fixo até uma época específica, conforme indicado por Morescki Jr (2015).

A taxa de variação temporal para o DCB entre dois rastreios quaisquer foi definida conforme 
apresentada na Eq. (21):

$$
\frac{\mathrm{dDCB}}{\mathrm{dt}}=\frac{\mathrm{DCB}_{1}-\mathrm{DCB}_{0}}{\mathrm{t}_{1-} \mathrm{t}_{0}}
$$

onde $\mathrm{DCB}_{0}$ é o valor do $\mathrm{DCB}$ inicial em nanossegundos, $\mathrm{DCB}_{1}$ é o valor do $\mathrm{DCB}$ da semana posterior ao $\mathrm{DCB}$ inicial e $t_{0}$ e $t_{1}$ representam o tempo do dia referente ao DCB inicial e da semana posterior, respectivamente, (ano, mês, dia, horas, minutos e segundos) em Dias Julianos Modificados (DJM). Então, a equação geral para a propagação dos DCBs é descrita pela Eq. (22):

$$
\mathrm{DCB}_{\mathrm{i}}=\mathrm{DCB}_{\mathrm{i}-1}+\frac{\mathrm{dDCB}}{\mathrm{dt}} \Delta \mathrm{t}
$$

sendo que o sub-índice $(\mathrm{i}), \mathrm{i}=1,2,3 \ldots$, corresponde à semana escolhida a ter seu DCB propagado e $\Delta$ t é o tempo de propagação em DJM.

Visando a validação da metodologia, os valores de DCB propagados foram comparados aos valores de DCB para a mesma época, utilizando como teste a estação da RBMC UFPR, visto que a mesma tem seus valores diários de DCB disponibilizados pelo IGS.

Com os valores calculados e propagados dos DCBs do receptor tornou-se possível o cálculo dos valores de TEC. Todos os cálculos do TEC foram feitos internamente pelo software RINEX_HO, utilizando a pseudodistância filtrada pela fase. Esses cálculos foram realizados utilizando-se máscara de elevação de $15^{\circ}$, isto é, todas as observáveis provenientes de satélites com elevação maior ou igual a $15^{\circ}$ foram corrigidas. Com os valores de TEC calculados, obtiveram-se os arquivos RINEX corrigidos, contendo as compensações dos efeitos de segunda e terceira ordem da refração ionosférica nas observáveis.

A fim de analisar a acurácia planialtimétrica obtida com as correções dos efeitos de ordem superior da refração ionosférica, usando-se os valores de TEC calculados a partir dos DCBs calculados e propagados, os experimentos descritos no Quadro 1 foram realizados. Os processamentos foram efetuados no software RTKLIB, PPP modo estático, com intervalo de aquisição dos dados de 15 segundos, máscara de elevação de $15^{\circ}$, com as efemérides e relógios dos satélites precisos e processados com a combinação linear livre de ionosfera (L3). As correções aos erros sistemáticos foram feitas dentro do software RTKLIB. Além disso, optou-se pelo processamento de uma e duas horas, onde foi escolhido o período das 15 às 17 horas local, horário onde há menos irregularidades na atmosfera, apesar da intensa atividade ionosférica no Brasil. Após a realização dos experimentos, fez-se a comparação das coordenadas obtidas com as coordenadas de referência, disponíveis em Huinca (2009).

Como ao final do processamento no PPP o software RTKLIB fornece as coordenadas geodésicas do ponto no Sistema de Referência Terrestre adotado nas efemérides precisas (ITRF14-IGS 14), referidas à época em que os dados foram coletados, foi necessário fazer a transformação das coordenadas para o Sistema de Referência SIRGAS 2000 na época 2000,4. O relacionamento entre a realização do ITRF e o SIRGAS 2000 se dá através de uma transformação de sete parâmetros (transformação de Helmert - três translações, três rotações e um fator de escala). Os parâmetros de transformação encontram-se no documento do PPP do IBGE (IBGE, 2017) e o modelo de velocidades utilizado foi o Vemos 2009. Ao final, as coordenadas foram transformadas para o Sistema Geodésico Local - SGL.

Após a obtenção das diferenças e dos desvios-padrão em cada experimento, a acurácia (REQM - Raíz do Erro Quadrático Médio) para cada componente do SGL foi calculada a partir das Eq. (23, 24 e 25) (MONICO et al., 2009):

$$
\begin{aligned}
& \operatorname{REQM}_{X}=\sqrt{\Delta X^{2}+\sigma_{\mathrm{x}_{-} \text {rastreio }}{ }^{2}+\sigma_{\mathrm{x}_{-} \text {PILAR }^{2}}}, \\
& \operatorname{REQM}_{Y}=\sqrt{\Delta \mathrm{Y}^{2}+\sigma_{\mathrm{y}_{-} \text {rastreio }}{ }^{2}+\sigma_{\mathrm{y}_{-} \text {PILAR }^{2}}}, \\
& \operatorname{REQM}_{\mathrm{Z}}=\sqrt{\Delta \mathrm{Z}^{2}+\sigma_{\mathrm{z}_{-} \text {rastreio }}{ }^{2}+\sigma_{\mathrm{z}_{-} \text {PILAR }^{2}}},
\end{aligned}
$$


onde, $\Delta \mathrm{X}, \Delta \mathrm{Y}$ e $\Delta \mathrm{Z}$ são as discrepâncias entre o valor obtido e o valor de referência em $\mathrm{X}, \mathrm{Y}$ e $\mathrm{Z}$, respectivamente; $\sigma_{\mathrm{X}_{\_} \text {rastreio }}, \sigma_{\mathrm{y}_{-} \text {rastreio }}$ e $\sigma_{\mathrm{z}_{-} \text {rastreio }}$ são os desvios-padrão em X, Y e Z, respectivamente, obtidos com o processamento; e $\sigma_{\mathrm{x}_{-} \text {PILAR }}{ }^{2},{\sigma_{\mathrm{y}_{-} \text {PILAR }}}^{2}$ e ${\sigma_{\mathrm{z}_{-} \text {PILAR }}}^{2}$ são os desvios-padrão das coordenadas do Pilar 1000, respectivamente.

\section{RESUlTAdOS OBTIDOS E ANÁLISES}

\subsection{Resultados obtidos no cálculo e propagação dos valores de DCB do receptor GPS}

Segundo mencionado anteriormente, o cálculo dos valores de DCB do receptor Leica 1200 foi realizado a partir da metodologia da Simples Diferença das observáveis livre de geometria, com rastreios de aproximadamente 24 horas, utilizando as pseudodistâncias filtradas pela fase. Os valores apresentaram um desvio padrão de $0,3639 \mathrm{~m}$. Na Figura 1 visualiza-se o comportamento do DCB do receptor GPS Leica 1200 para o período analisado.

Figura 1 - DCB do receptor Leica 1200.

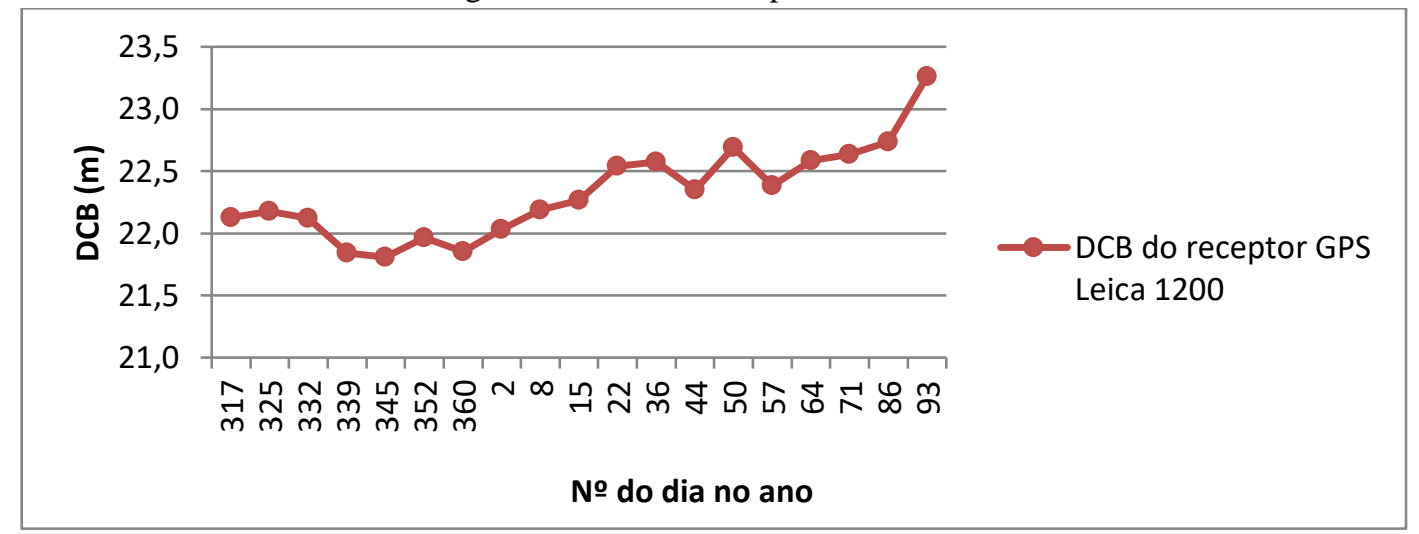

Fonte: Os autores (2020).

Com a finalidade de validar a ideia de propagação de valores de DCB, testes foram realizados utilizando os 31 dias de dados do mês de agosto de 2017 da estação UFPR. Uma vez que os valores de DCB para o receptor que operava nesta estação são calculados pelo IGS e disponibilizados nos arquivos IONEX, os valores de DCB propagados a partir do primeiro dia foram comparados com os disponibilizados. Na figura 2 é possível ver a discrepância entre os valores do IGS e os propagados.

Os resultados revelam uma discrepância máxima de $0,867 \mathrm{~ns}$, que representa $0,260 \mathrm{~m}$, entre o valor determinado pelo IGS e o valor propagado por integração numérica. Este valor é considerado aceitável, visto que é compatível com a acurácia com que os valores de TEC são estimados pelo IGS, que é de 2 à 8 TECU (IGS, 2018). Sabe-se que 1 TECU induz a um erro de cerca de $0,16 \mathrm{~m}$ e $0,27 \mathrm{~m}$ nas observáveis das portadoras L1 e L2, respectivamente (MATSUOKA; CAMARGO, 2004). 
Figura 2 - Discrepância entre o valor do DCB calculado pelo IGS e propagado para a estação UFPR.

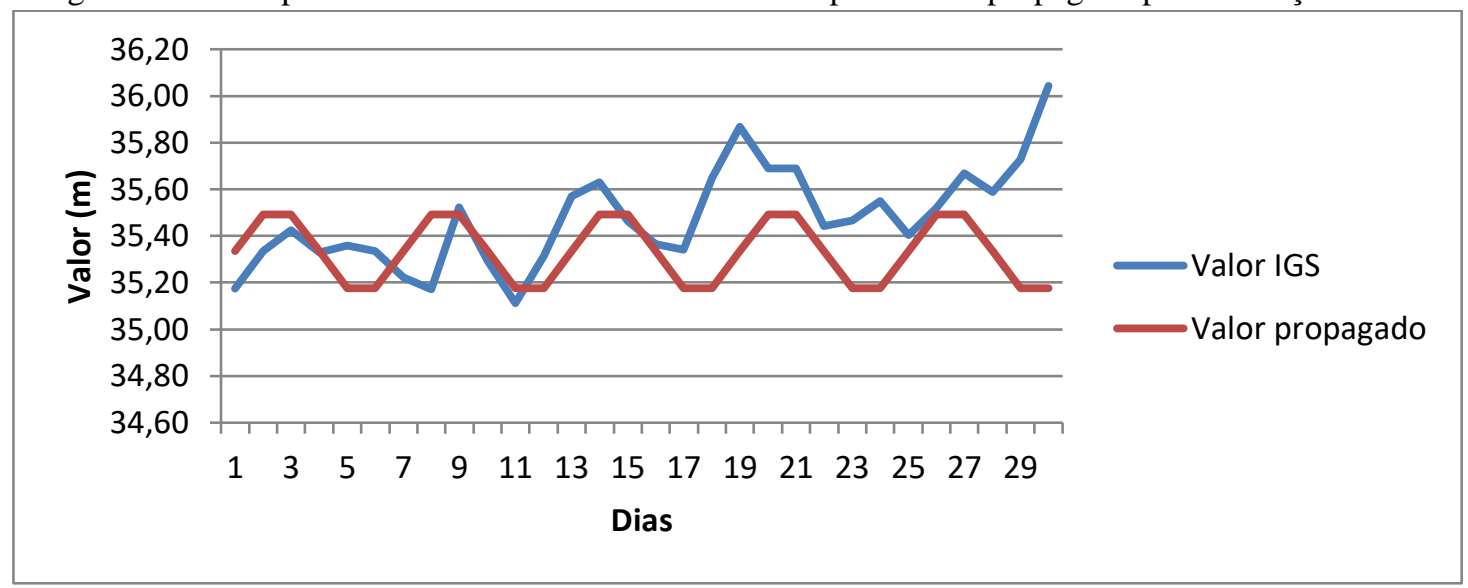

Fonte: Os autores (20120).

\subsection{Resultados obtidos nos experimentos com duração de uma e duas horas no Pilar 1000}

Posteriormente aos processamentos com duração de uma e duas horas, os valores de REQM para as componentes do SGL foram calculados com base nos desvios-padrão e nos deslocamentos em relação às coordenadas de referência do Pilar 1000. Após a correção dos efeitos de ordem superior da refração ionosférica, as pseudodistâncias entre os arquivos RINEX corrigidos e não corrigidos apresentaram uma diferença na ordem do centímetro.

Para os experimentos 1 e 2 realizados com PPP de 1 hora, a média do desvio-padrão para a componente $\mathrm{X}$ foi de $0,0556 \mathrm{~m}$, para a componente $\mathrm{Y}$ foi de $0,0827 \mathrm{~m}$ e para a componente $\mathrm{Z}$ foi de $0,1055 \mathrm{~m}$. Para os experimentos 1 e 2 realizados com PPP de 2 horas, a média do desvio-padrão da componente $X$ foi de 0,0245 $\mathrm{m}$, para a componente $\mathrm{Y}$ foi de $0,0489 \mathrm{~m}$ e para a componente $\mathrm{Z}$ foi de $0,0481 \mathrm{~m}$. Como os valores dos desviospadrão tanto para 1 hora como para 2 horas são menores que os valores de $\Delta$, então os erros aleatórios são menores que os sistemáticos. Com a melhoria nos $\Delta$, houve melhoria no tratamento dos erros sistemáticos dos efeitos de ordem superior da refração ionosférica.

Tabela 1 - Média dos REQM para os experimentos 1 e 2, com processamento de uma hora.

\begin{tabular}{cccc|ccc}
\hline & \multicolumn{3}{c}{ 1 HORA } & \multicolumn{3}{c}{ 2 HORAS } \\
\hline & $\mathbf{X}(\mathbf{m})$ & $\mathbf{Y}(\mathbf{m})$ & $\mathbf{Z}(\mathbf{m})$ & $\mathbf{X}(\mathbf{m})$ & $\mathbf{Y}(\mathbf{m})$ & $\mathbf{Z}(\mathbf{m})$ \\
\hline Experimento 1 & 0,6956 & 0,3450 & 0,4144 & 0,6552 & 0,3097 & 0,3672 \\
\hline Experimento 2 & 0,6942 & 0,3444 & 0,4132 & 0,6549 & 0,3113 & 0,3662 \\
\hline
\end{tabular}

Fonte: Os autores (2020).

Ao analisar a Tabela 1, nota-se que a diferença das médias dos REQM entre os casos ficou na ordem do milímetro para as três componentes. A acurácia para o experimento com correção dos efeitos de ordem superior da refração ionosférica se mostrou melhor nas três componentes do que com correção apenas dos efeitos de primeira ordem. A componente com menor acurácia no caso dos experimentos 1 e 2 foi a componente $\mathrm{X}$, a qual obteve o maior valor de REQM dentre as outras. Percebe-se que o processamento de duas horas se mostrou com melhor acurácia do que de apenas uma hora, pois os REQM das componentes X, Y e Z ficaram mais próximos de zero.

Para os experimentos 3 e 4 realizados com PPP de 1 hora, a média do desvio-padrão para a componente $\mathrm{X}$ foi de $0,0556 \mathrm{~m}$, para a componente $\mathrm{Y}$ foi de $0,0823 \mathrm{~m}$ e para a componente $\mathrm{Z}$ foi de $0,1060 \mathrm{~m}$. Para os PPPs de 2 horas, a média do desvio-padrão da componente $X$ foi de $0,0240 \mathrm{~m}$, para a componente $\mathrm{Y}$ foi de 0,0485 m e para a componente $\mathrm{Z}$ foi de $0,0480 \mathrm{~m}$. Visto que os valores dos desvios-padrão são menores que os valores de $\Delta$, logo os erros aleatórios são menores que os sistemáticos, portanto houve melhoria no tratamento dos erros sistemáticos dos efeitos de ordem superior da ionosfera.

Os resultados obtidos nos experimentos 3 e 4 são muito próximos aos resultados das semanas coincidentes do experimento 2 . Isso se deve ao fato de que a propagação ficou tão próxima quanto se esperava, 
sendo assim, o objetivo da propagação foi alcançado.

Tabela 2 - Média dos REQM para os experimentos 3 e 4, com processamento de uma hora.

\begin{tabular}{cccc|ccc}
\hline & \multicolumn{3}{c|}{ 1 HORA } & \multicolumn{3}{c}{ 2 HORAS } \\
\hline & $\mathbf{X}(\mathbf{m})$ & $\mathbf{Y}(\mathbf{m})$ & $\mathbf{Z}(\mathbf{m})$ & $\mathbf{X}(\mathbf{m})$ & $\mathbf{Y}(\mathbf{m})$ & $\mathbf{Z}(\mathbf{m})$ \\
\hline $\mathbf{3}^{\mathbf{a}}$ semana & 0,6035 & 0,2973 & 0,4567 & 0,6511 & 0,3031 & 0,4341 \\
\hline $\mathbf{4}^{\mathbf{a}}$ semana & 0,5741 & 0,3901 & 0,3697 & 0,5360 & 0,3137 & 0,2645 \\
\hline
\end{tabular}

Fonte: Os autores (2020).

Ao analisar a Tabela 2, percebe-se que a diferença das médias dos REQM entre os experimentos 3 e 4 ficou na ordem do centímetro para as três componentes, nos resultados de 1 hora. Nos resultados de 2 horas, ficou na ordem do decímetro para as componentes $\mathrm{X}$ e $\mathrm{Z}$ e na ordem do centímetro para a componente $\mathrm{Y}$. Embora na acurácia da componente $\mathrm{Y}$ houve uma piora, nas componentes $\mathrm{X}$ e $\mathrm{Z}$ houve uma melhora para o caso do experimento 4. Isso se deve possivelmente ao comportamento não linear dos DCBs. A componente com menor acurácia é a $\mathrm{X}$ nos experimentos. Caso fosse necessário, seria possível utilizar os resultados com os valores de DCBs propagados. Além do mais, as médias dos REQM obtidas com os processamentos de duas horas ficaram, no geral, melhores do que aquelas obtidas com os processamentos de uma hora.

As Figuras 3, 4 e 5 representam as variações dos REQM das componentes X, Y e Z, respectivamente, e na Figura 6 encontram-se as diferenças entre os REQM das componentes $\mathrm{X}, \mathrm{Y}$ e Z, para os experimentos 1 e 2 do Quadro 1. Na Figura 7, estão descritos os valores de REQM para X, Y, Z em relação aos experimentos 3 e 4 do Quadro 1.

Figura 3 - Valores de REQM X para 12 horas de processamento - experimentos 1 e 2.
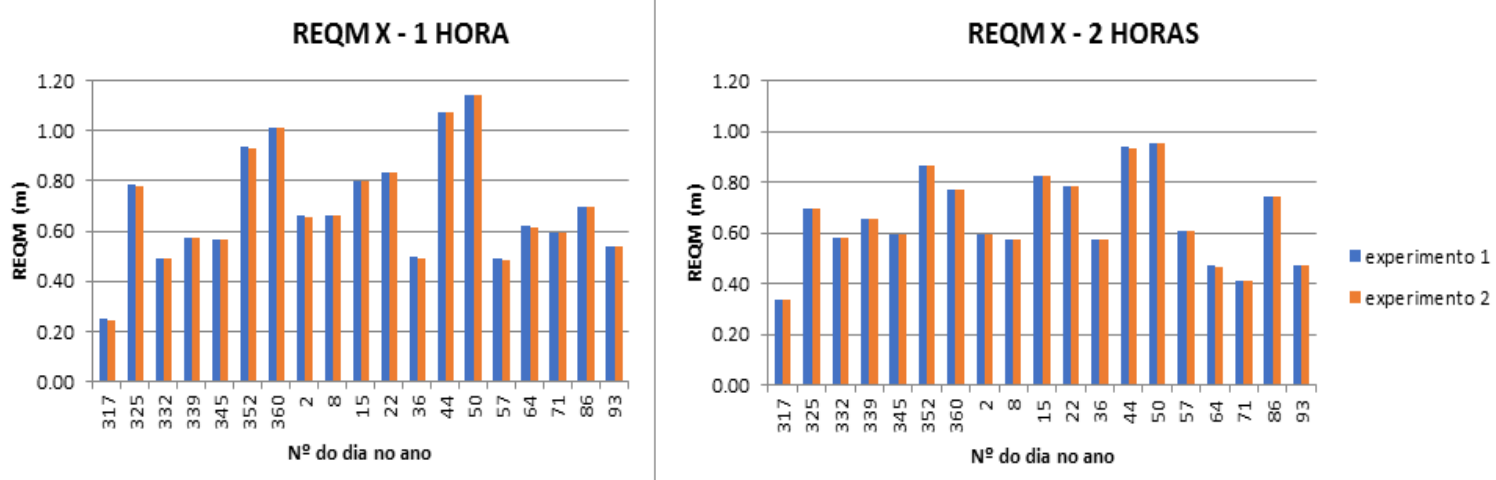

Fonte: Os autores (2020).

Nota-se na Figura 3 que o maior valor de REQM para 1 hora é maior que 1,1 $\mathrm{m}$ no dia 50 e o menor valor é de aproximadamente $0,2 \mathrm{~m}$ no dia 317 . O maior valor de REQM para 2 horas é de aproximadamente $0,9 \mathrm{~m}$ no dia 50, sendo que o menor valor é de aproximadamente $0,3 \mathrm{~m}$ encontrado no dia 317 . Em geral, percebe-se que os valores do experimento 2 são menores que do experimento 1, ou seja, são mais acurados.

Figura 4 - Valores de REQM Y para 1 e 2 horas de processamento - experimentos 1 e 2.

REQM Y - 1 HORA

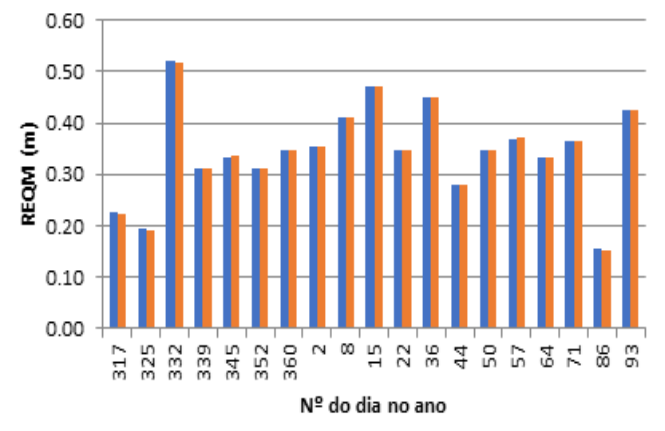

REQM Y - 2 HORAS

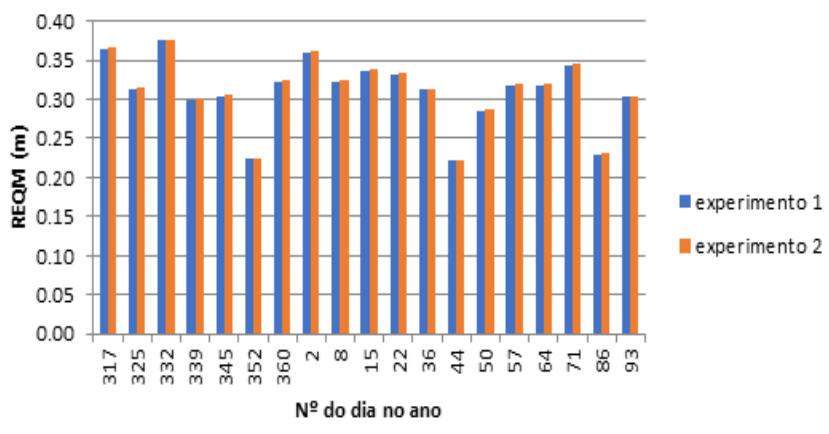

Fonte: Os autores (2020). 
Observa-se na Figura 4 que, para 1 hora, no dia 332 obteve-se o maior valor de REQM, sendo de aproximadamente $0,5 \mathrm{~m}$. O menor valor foi registrado no dia 86, sendo de aproximadamente 0,2 m. Para 2 horas, no dia 332 obteve-se o maior valor de REQM, sendo de aproximadamente $0,4 \mathrm{~m}$. O menor valor foi registrado no dia 44, sendo de aproximadamente $0,2 \mathrm{~m}$. Os resultados do experimento 2 são mais acurados do que do experimento 1 .

Figura 5 - Valores de REQM Z para 1 e 2 horas de processamento - experimentos 1 e 2.

REQMZ - 1 HORA

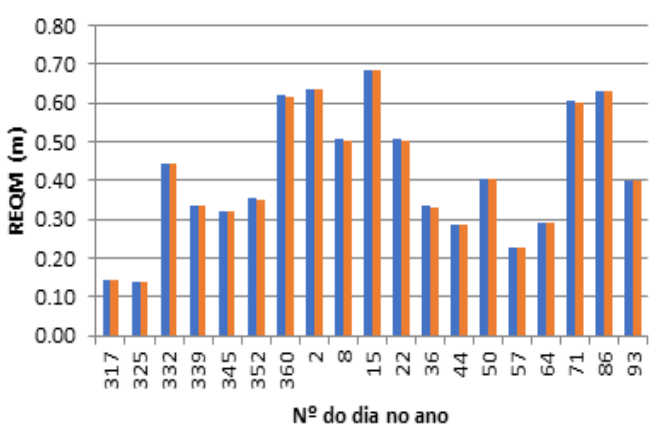

REQM Z - PROCESSAMENTO DE 2 HORAS

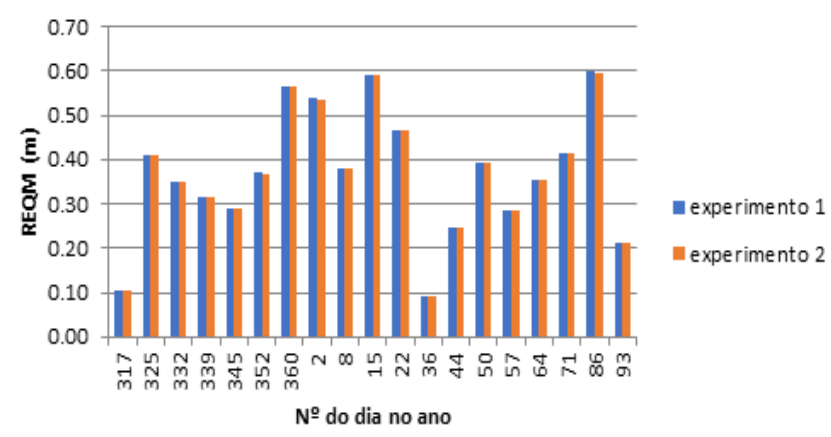

Fonte: Os autores (2020).

Constata-se observando a Figura 5 que o maior valor de REQM para 1 hora é de aproximadamente 0,7 $\mathrm{m}$ no dia 15 , sendo que o menor valor é de aproximadamente 0,1 encontrado no dia 325 . Para 2 horas, a maior diferença entre os REQM da componente $\mathrm{Z}$ é de $0,0024 \mathrm{~m}$ no dia 352 e a menor é de aproximadamente zero no dia 44. Nota-se também que os resultados do experimento 1 são menos acurados do que os do experimento 2 , pois aqueles apresentam valores maiores do que estes.

Figura 6 - Diferenças entre os REQM X, Y e Z dos experimentos 1 e 2 para o processamento de 1 e 2 horas.

1 HORA

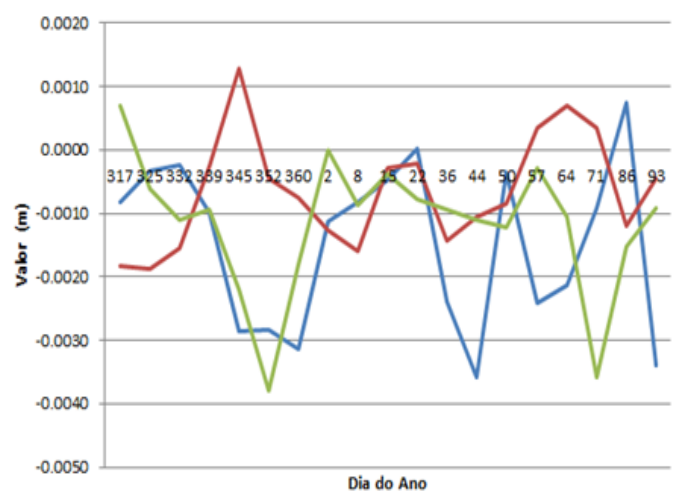

2 HORAS

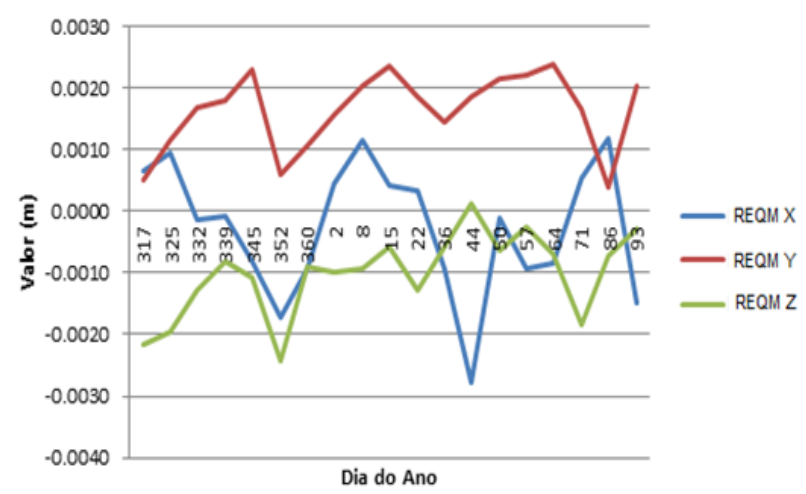

Fonte: Os autores (2020).

Na Figura 6 observa-se que a maior diferença entre os REQM para 1 hora da componente $X$ é de $0,0036 \mathrm{~m}$ no dia 44 e a menor é de aproximadamente zero no dia 22 ; na componente $\mathrm{Y}$ é de $0,0019 \mathrm{~m}$ no dia 325 e a menor é de $0,0003 \mathrm{~m}$ no dia 71 e; na componente $\mathrm{Z}$ é de $0,0378 \mathrm{~m}$ no dia 352 e a menor é de aproximadamente zero no dia 2. Para 2 horas, tem-se que a maior diferença entre os REQM da componente $X$ é de $0,0028 \mathrm{~m}$ no dia 44 e a menor é de aproximadamente zero nos dias 339 e 50, na componente Y é de 0,0024 $\mathrm{m}$ no dia 64 e a menor é de aproximadamente $0,0004 \mathrm{~m}$ no dia 86 e na componente $\mathrm{Z}$ o maior valor de REQM é de aproximadamente $0,6 \mathrm{~m}$ no dia 86 , sendo que o menor valor é de aproximadamente 0,1 encontrado no dia 36. 
Figura 7 - REQM X, Y e Z para 1 e 2 horas de processamento - experimentos 3 e 4.
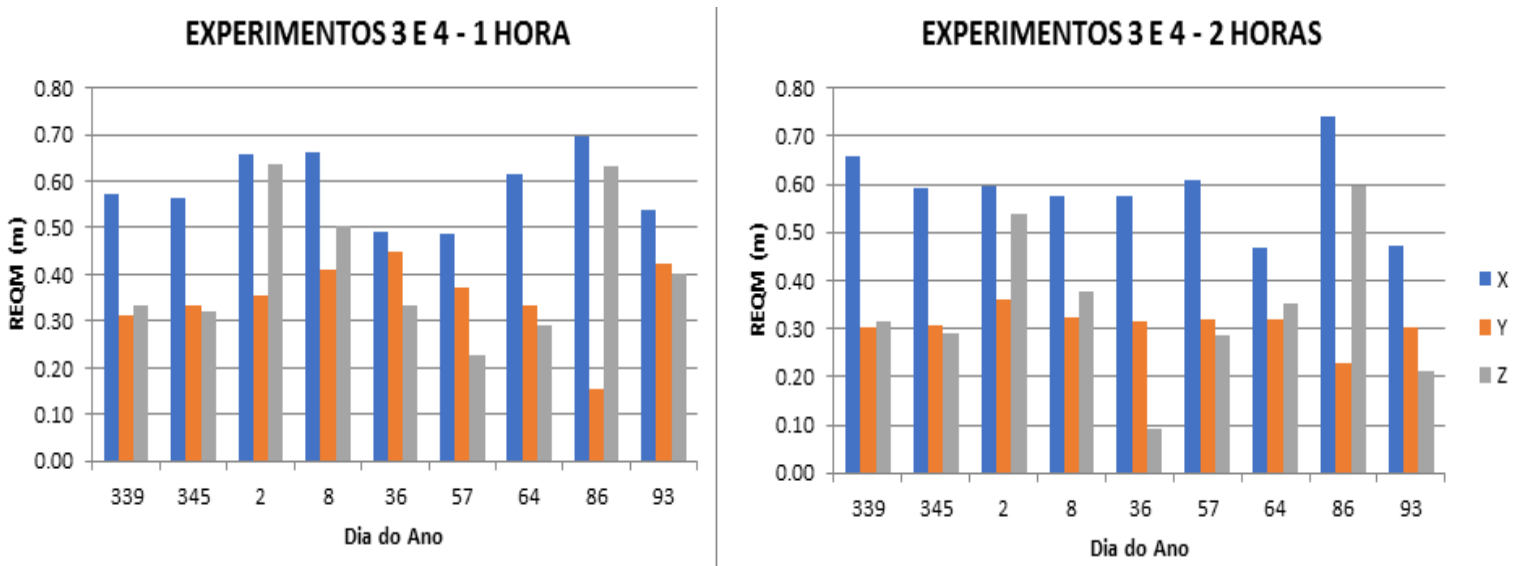

Fonte: Os autores (2020).

Observa-se na Figura 7 que os valores de REQM de $X$ tanto para 1 hora como para 2 horas são maiores do que Y e Z, da mesma forma como observado nas Figuras 3, 4 e 5. Para 1 hora, o maior valor de REQM na componente $\mathrm{X}$ é do dia 86 , sendo de $0,6963 \mathrm{~m}$ e o menor é do dia 57 , sendo de $0,4856 \mathrm{~m}$. Já para Y, o maior valor é do dia 36 , sendo de $0,4481 \mathrm{~m}$ e o menor é do dia 86 , sendo de $0,1529 \mathrm{~m}$. Para a componente $\mathrm{Z}$, o maior valor é no dia 2 , sendo de $0,6368 \mathrm{~m}$ e o menor valor é no dia 57 , sendo de $0,2251 \mathrm{~m}$. Para 2 horas, tem-se que o maior valor de REQM na componente $\mathrm{X}$ é do dia 86 , sendo de $0,7419 \mathrm{~m}$ e o menor é do dia 64 , sendo de $0,4687 \mathrm{~m}$. Já para $\mathrm{Y}$, o maior valor é do dia 2 , sendo de $0,3609 \mathrm{~m}$ e o menor é do dia 86 , sendo de $0,2302 \mathrm{~m}$. Para a componente $\mathrm{Z}$, o maior valor é no dia 86 , sendo de $0,5967 \mathrm{~m}$ e o menor valor é no dia 36 , sendo de $0,0903 \mathrm{~m}$.

\section{CONCLUSÃO}

A proposta apresentada nesta pesquisa visou aplicar a metodologia da simples diferença no cálculo do DCB do receptor GPS Leica 1200 para utilizá-lo no cálculo dos efeitos de ordem superior da refração ionosférica e analisar o ganho obtido em comparação com a não correção de tais efeitos. Também foi investigada a possibilidade de propagação dos valores do DCB do receptor a fim de otimizar o tempo gasto com idas a campo.

A partir do resultado do cálculo dos DCBs do receptor Leica 1200, calculou-se o desvio padrão a fim de quantificar a dispersão dos DCBs calculados com o método apresentado, o qual apresentou um valor de $0,3639 \mathrm{~m}$.

Experimentos foram realizados visando a avaliação do método proposto para a propagação numérica dos valores de DCB. Os resultados obtidos com a propagação foram comparados com dados provenientes do IGS para a estação UFPR, e se mostraram adequados, com uma diferença máxima de 0,260 m, permitindo assim uma avaliação positiva, visto que o valor é compatível com a precisão com que os valores de TEC são estimados pelo IGS. Ainda na etapa de validação do experimento, foram realizados processamentos PPP no modo estático pela plataforma online IBGE-PPP, utilizando dados adquiridos com o DCB propagado e com o DCB proveniente do IGS para a mesma estação. A média dos REQM para a latitude, longitude e altura no PPP são, respectivamente, $0,00252 \mathrm{~m}, 0,01404 \mathrm{~m}$ e $0,01543 \mathrm{~m}$.

Para avaliar a acurácia do método proposto, foram feitos processamentos PPP modo estático no software RTKLIB com uma e duas horas de duração, seguindo os experimentos do Quadro 1. Os valores de REQM foram calculados com base nas discrepâncias entre as coordenadas obtidas e as de referência, e seus desvios-padrão.

Ao analisar os resultados dos experimentos, foi possível alcançar os objetivos propostos na pesquisa. No primeiro experimento, foi feito um processamento PPP de uma e depois duas horas com correção apenas dos efeitos de primeira ordem da refração ionosférica. Este experimento revelou que os PPPs com duração de duas horas obtiveram maior acurácia do que os de uma hora. Na componente $\mathrm{X}$, houve uma melhora de 5,8\%; 
na componente $\mathrm{Y}$, de $10,2 \%$; e na componente $\mathrm{Z}$, de $11,4 \%$.

No segundo experimento, realizou-se outro processamento PPP, também de uma e depois duas horas, desta vez com correções de primeira, segunda e terceira ordens da refração ionosférica, utilizando o DCB do receptor que foi calculado previamente. Os PPPs de duas horas se mostraram mais acurados do que os de uma hora. Na componente X, houve uma melhora de $5,7 \%$; na componente $\mathrm{Y}$, de $9,6 \%$ e na componente $\mathrm{Z}$, de $11,4 \%$.

Como já era esperado, os resultados obtidos no segundo experimento foram melhores dos que os obtidos no primeiro experimento, visto que foram feitas as correções de ordem superior da refração ionosférica. A diferença entre o primeiro e o segundo experimento, é da ordem do milímetro e, para o processamento com duração de duas horas, a diferença é $0,27 \mathrm{~mm}$ para $X, 1,64 \mathrm{~mm}$ para $\mathrm{Y}$ e 1,02 $\mathrm{mm}$ para $\mathrm{Z}$.

O terceiro e quarto experimentos são PPPs com correções de primeira ordem e de ordem superior da ionosfera, utilizando o DCB do receptor propagado para 3 e 4 semanas, respectivamente. Uma vez que o método foi validado, esses experimentos foram realizados com confiança. Em ambos os experimentos foram feitos novos PPPs, também com uma e duas horas de processamento. No experimento 3, houve uma piora de $7,9 \%$ e $1,9 \%$ nas componentes $\mathrm{X}$ e $\mathrm{Y}$, respectivamente, e uma melhora de $4,9 \%$ na componente $\mathrm{Z}$, quando comparados os resultados de duas horas com os de uma hora. Já no experimento 4, os resultados com processamento de duas horas apresentaram uma melhora de $6,6 \%, 19,6 \%$ e $28,4 \%$ para as componentes X, Y e Z, respectivamente. As diferenças entre os valores obtidos utilizando o DCB propagado e o DCB calculado são próximas de zero. Os resultados revelam uma acurácia tão próxima quanto se era esperada.

A metodologia exposta neste trabalho de pesquisa apresenta contribuição quando se deseja maior acurácia para realização e densificação de referenciais, bem como monitoramento de estruturas, movimentação de placas tectônicas e campos de velocidade, dentre outras.

\section{Agradecimentos}

Os autores agradecem à CAPES (Coordenação de Aperfeiçoamento de Pessoal de Nível Superior) número do processo 1711249 pela concessão de bolsa de estudo durante todo o período da pesquisa.

\section{Contribuição dos Autores}

Os autores Cordeiro, Rodrigues e Ferreira executaram conjuntamente as etapas de conceptualização e validação. Cordeiro e Rodrigues atuaram na análise formal, metodologia e redação - revisão e edição. Cordeiro foi responsável pela curadoria dos dados, investigação, administração do projeto, visualização e redação minuta inicial. Rodrigues atuou na supervisão.

\section{Conflitos de Interesse}

Os autores declaram que não há conflitos de interesse.

\section{Referências}

BASSIRI, S.; HAJJ, G. A. Higher-Order ionospheric effects on the Global Positioning System observables and means of modeling them. Manuscripta geodaetica, v. 18, n. 5, p. 280-280, 1993.

CAMARGO, P. O. Modelo regional da ionosfera para uso em posicionamento com receptores GPS de uma frequência. 209 f. Tese (Doutorado em Ciências Geodésicas) - Universidade Fedral do Paraná, Curitiba, 1999.

CAMARGO, P. O.; ARANA, D.; PEREIRA, V. A. S. Erro sistemático relativo devido ao hardware dos receptores. III Simpósio Brasileiro de Geomática, Presidente Prudente, v. 1, p. 268-273, 2012.

CHOI, B. K.; CHO, J. H.; LEE, S. J. Estimation and analysis of GPS receiver Differential Code Biases using KGN in Korean peninsula. Advances in Space Research, v. 47, n. 9, p. 1590-1599, 2011. 
COLLINS, P.; BISNATH, S.; LAHAYE, F.; HÉROUX, P. Undifferenced GPS ambiguity resolution using the decoupled clock model and ambiguity datum fixing. Navigation, v. 57, n. 2, p. 123-135, 2010.

FEHLBERG, E. Classical Fifth-, Sixth-, Seventh-, and Eighth-Order Runge-Kutta formulas with stepsize control. Washinton. D.C. NASA (NASA TR R-287), 1968.

FRITSCHE, M.; DIETRICH, R.; KNÖFEL, C.; RÜLKE, A.; VEY, S.; ROTACHER, M.; STEIGENBERGER, P. Impact of Higher-Order ionospheric terms on GPS estimates. Geophysical Research Letters, v. 32, 2005.

GE, Y.; ZHOU, F.; SUN, B.; WANG, S.; SHI, B. The impact of satellite time group delay and interfrequency Differential Code Bias corrections on multi-GNSS combined positioning. Sensors, v. 17, n. 3, p. 602, 2017.

GOAD, C. C.; YANG, M. On automatic precision airborne GPS positioning. Proc KIS94. Banff, p. 131138, 1994.

HEGARTY, C.; POWERS, E. D.; FONVILLE, B. Accounting for timing biases between GPS, modernized GPS, and Galileo signals. Naval Observatory Washington DC, 2005.

HERNÁNDEZ-PAJARES, M.; JUAN, J. M.; SANZ, J. New approaches in global ionospheric determination using ground GPS data. Journal of Atmospheric and Solar-Terrestrial Physics, v. 61, n. 16, p. 12371247, 1999.

HONG, C. Efficient GPS receiver DCB estimation for ionosphere modeling using satellite-receiver geometry changes. Tese de Doutorado - Ohio State University, Ohio, 2007.

HONG, C.; GREJNER-BRZEZINSKA, D. A.; KWON, J. H. Efficient GPS receiver DCB estimation for ionosphere modeling using satellite-receiver geometry changes. Earth Planets Space,v.60, p. e25-e28, 2008.

HUINCA, S. C. M. Calibração relativa de antenas GNSS na BCAL/UFPR. 127 f. Dissertação de Mestrado - Universidade Federal do Paraná, Curitiba, 2009.

INSTITUTO BRASILEIRO DE GEOGRAFIA E ESTATÍSTICA (IBGE). Manual do usuário aplicativo online IBGE-PPP: Versão Abril 2017. Disponível em: <https://ww2.ibge.gov.br/home/geociencias/geodesia/ppp/manual_ppp.pdf>. Acesso em: 20 out. 2018.

INTERNATIONAL EARTH ROTATION AND REFERENCE SERVICE (IERS). IERS Conventions 2010. Disponível em: <http://www.iers.org/IERS/EN/Publications/TechnicalNotes/tn36.html>. Acesso em: 27 jun. 2018.

INTERNATIONAL GNSS SERVICE (IGS). Disponível em: <http://www.igs.org/products/data>. Acesso em: 7 abr. 2018.

KLOBUCHAR, J. A. Ionospheric effects on GPS. GPS World Magazine, Cleveland, v. 2, n. 4, p. 48-51, 1991.

LEICK, A. GPS Satellite Surveying. $2^{\text {a }}$ ed. New York: John Wiley \& Sons, 560 p., 1995.

LI, H.; LI, B.; LOU, L.; YANG, L.; WANG, J. Impact of GPS Differential Code Bias in dual- and triplefrequency positioning and satellite clock estimation. GPS Solutions, p. 897-903, 2017.

MARQUES, H. A. Influência da ionosfera no posicionamento GPS: Estimativa dos resíduos no contexto de duplas diferenças e eliminação dos efeitos de $2^{\mathbf{a}}$ e $3^{\mathbf{a}}$ ordem. 152 f., Dissertação de Mestrado Universidade Estadual Paulista, Presidente Prudente, 2008.

MARQUES, H. A.; MONICO, J. F. G.; MARQUES, H. A. S.; AQUINO, M. Análise dos efeitos ionosféricos de ordem superior no ciclo solar 24 e influência no posicionamento GNSS absoluto. Boletim de Ciências Geodésicas, v. 20, n. 4, p. 879-901, 2014.

MATSUOKA, M. T.; CAMARGO, P. O. Cálculo do TEC usando dados de receptores GPS de dupla frequência para produção de mapa da ionosfera para região brasileira. Revista Brasileira de Cartografia, v. 56, n. 1, p. 14-27, 2004.

MONICO, J. F. G.; DAL PÓZ, A. P.; SANTOS, M. C.; OLIVEIRA, L. C. Acurácia e precisão: revendo os conceitos de forma acurada. Boletim de Ciências Geodésicas, v. 15, n. 3, 2009. 
MORESCKI JUNIOR, L. F. M. Determinação dos parâmetros PCOs e PCVs de antenas GNSS utilizando propagação numérica. 135 f. Tese de Doutorado - Universidade Federal do Paraná, Curitiba, 2015.

ODIJK, D. Fast precise GPS positioning in the presence of ionospheric delays. Publications on Geodesy, 52 , 2002.

PROL, F. S.; CAMARGO, P. O. Estimativa da tendência diferencial do código nos receptores GNSS. Boletim de Ciências Geodésicas, v. 20, n. 4, 2014.

SCHAER, S. Mapping and predicting the earth's ionosphere using the Global Positioning System.

Ph.D. Thesis, Astronomisches Institute, Universität Bern, Switzerland, 1999..

TAKASU, T. RTKLIB: Open source program package for RTK-GPS. Proceedings of the FOSS4G, 2009.

WILSON, B.; MANNUCCI, A. Extracting ionospheric measurements from GPS in the presence of AntiSpoofing. Proceedings of ION GPS-94, p. 1599-1608, 1994.

\section{Biografia do autor principal}

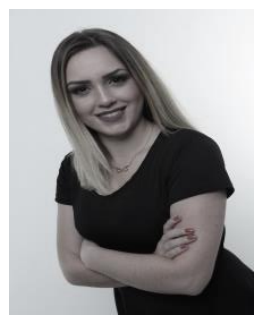

Fabiane Piovesan de Moraes Cordeiro nasceu em Curitiba - PR, no ano de 1993. Possui graduação em Engenharia Cartográfica e de Agrimensura pela Universidade Federal do Paraná - UFPR (2016), Curitiba. Mestrado em Ciências Geodésicas com ênfase em Geodésia Espacial pela mesma instituição (2019). Atualmente trabalha com consultoria em engenharia e cartografia em Curitiba. Tem interesse nos seguintes temas: Posicionamento e Sensoriamento Remoto Geodésico e Monitoramento da Atmosfera com GNSS. 